survivors. ${ }^{4}$ Recent larger studies in Edmonton ${ }^{11}$ and Pittsburgh, ${ }^{2}$ however, have failed to show any correlation between antenatal adverse factors and the outcome in survivors of asphyxia. In studies in monkeys total asphyxia mostly damaged the brain stem whereas long-term partial intrauterine asphyxia damaged mainly the cerebral hemispheres, cerebellum, and basal ganglia. ${ }^{12}$ The latter pattern most closely resembles the pattern of human brain damage.

Finally, can neonatal examination predict long-term outcome? Most asphyxiated babies who are neurologically abnormal soon after birth recover completely. ${ }^{31314}$ In Manchester 55 babies were thought to show severe neurological abnormality in the first few days of life. ${ }^{13}$ Two died within the first two days, but of the 53 survivors only four had a definite neurological disorder on follow-up, and in only one was the disorder severe. The babies were divided into four categories on the basis of activity and tone: hyperexcitable; apathetic; apathetic early but hyperexcitable after two or three days; and normal tone with other neurological abnormality. Three of the four babies who had definite neurological abnormality at follow-up came from the group of seven who were initially apathetic and hypotonic but after two or three days became hyperexcitable and showed extensor hypertonia. An earlier Edinburgh series ${ }^{3}$ also found that this group of babies was at highest risk of later handicap. In that series certain clinical features were found to be predictive in combination: feeding difficulties, apnoeic spells, apathy, convulsions, hypothermia, cerebral cry, and persistent vomiting. Babies with five or more of these had a $90 \%$ risk of death or serious handicap. With only one symptom no baby died or had serious handicap.

Convulsions after birth asphyxia are of serious significance, especially when they are multiple and recur over a prolonged period. In the Collaborative Project Study $30 \%$ of babies with convulsions died and $18 \%$ of the survivors had severe handicap, ${ }^{14}$ but in a more recent study in Manchester only one of 22 babies who had convulsions had a severe neurological abnormality at follow-up. ${ }^{13}$

What, then, does all this mean in practice? Firstly, severe birth asphyxia does not have a universally gloomy prognosis, and skilled resuscitation should be available for all babies. The prognosis with prolonged asphyxia may be less favourable, but a decision to stop resuscitation should be made only after considering possible treatable causes. Failure to show any response after 30 minutes, however, is probably associated with a bad prognosis. Most survivors of birth asphyxia are normal, but a few are very severely handicapped. Lesser degrees of behavioural or educational abnormality in survivors have not been convincingly shown, though some of them have speech and language problems and may need special education. In the newborn baby convulsions after birth asphyxia are of serious import, especially if they are multiple and persistent, and the combination of early apathy followed after two or three days by hyperexcitability seems to carry a particularly poor prognosis.

D P ADDY

Consultant paediatrician,

Dudley Road Hospital,

Birmingham B18 7QH

1 Nelson KB, Ellenberg JH. Apgar scores as predictors of chronic neurologic disability. Pediatrics $1981 ; 68: 36-44$.

${ }^{2}$ Mulligan JC, Painter MJ, O'Donoghue PA, MacDonald HM, Allen AC, Taylor PM. Neonatal asphyxia. II. Neonatal mortality and long-term sequelae. F Pediat 1980;96:903-7.

${ }^{3}$ Brown JK, Purvis RJ, Forfar JO, Cockburn F. Neurological aspects of perinatal asphyxia. Dev Med Child Neurol 1974;16:567-80.

${ }^{4}$ Scott H. Outcome of very severe birth asphyxia. Arch Dis Child 1976;51: 712-6.
5 Thomson AJ, Searle M, Russell G. Quality of survival after severe birth asphyxia. Arch Dis Child 1977;52:620-6.

6 Steiner H, Neligan G. Perinatal cardiac arrest: quality of the survivors. Arch Dis Child 1975;50:696-702.

2 Apgar V. A proposal for a new method of evaluation of the newborn infant. Current Researches in Anaesthesia and Analgesia 1953;32:260-7.

${ }^{8}$ Dweck HS, Huggins W, Dorman LP, Saxon SA, Benton JW, Cassady G. Developmental sequelae in infants having suffered severe perinatal asphyxia. Am 7 Obstet Gynecol 1974;119:811-5.

${ }^{9}$ D'Souza SW, McCartney E, Nolan M, Taylor IG. Hearing, speech, and language in survivors of severe perinatal asphyxia. Arch Dis Child $1981 ; \mathbf{5 6}: 245-52$

10 Niswander KR, Friedman EA, Berendes H. Do placenta previa, abruptio placentae and prolapsed cord cause neurologic damage to the infant who survives? In: MacKeith $\mathrm{R}$, Bax, M, eds. Studies in infancy. London: Heinemann Medical, 1968:78-83. (Clinics in Developmental Medicine No 27.)

11 Finer NN, Robertson CM, Richards .RT, Pinnell LE, Peters KL. Hypoxic-ischaemic encephalopathy in term neonates: perinatal factors and outcome. $\mathcal{F}$ Pediatr 1981;98:112-7.

12 Adamsons K, Myers RE. Perinatal asphyxia. Causes, detection and neurologic sequelae. Pediatr Clin North $A m$ 1973;20:465-80.

${ }^{13}$ De Souza SW, Richards B. Neurological sequelae in newborn babies after perinatal asphyxia. Arch Dis Child 1978;53:564-9.

${ }^{14}$ Nelson KB, Ellenberg JH. Neonatal signs as predictors of cerebral palsy. Pediatrics $1979 ; 64: 225-32$.

\section{Information overload: solution by quality?}

Are there too many journals for even the most enthusiastic reader? Are important discoveries being missed because vital papers are buried in a mass of inferior ones ? Could and should limits be set on the numbers of articles or journals published? Though we may suspect that the answer to all these questions is yes, an opposite and optimistic conclusion emerges from an important new book: all these problems can be overcome by ignoring quantity and concentrating on quality. In this way, Coping with the Biomedical Literature concludes, the individual can still keep up to date by scanning relatively few journals, supplementing his efforts with specific searches in review articles, citation lists, and computer printouts as well as conversation in the "invisible college" of colleagues and fellow researchers. ${ }^{1}$

On the face of it the problems are daunting: for biomedicine there are now over 20000 journals, almost all of them received at the National Library of Medicine, in Bethesda, USA; 3200 of these are included in its Medical Literature and Retrieval System (Medlars) and 1000 in the Science Citation Index. The number of journals increases by $6-7 \%$ a year, doubles every 10-15 years, and increases tenfold every $35-50$ years. At the opening of this century there were roughly 1000 biomedical journals; 30 years ago there were 4000 and 10 years ago $14000 .^{2}$ True, some journals cease publication, but at a rate insufficient to affect this exponential growth.

There has been no lack of suggestions for dramatic action to restrict this growth, both Bernal ${ }^{3}$ and Fox $^{4}$ arguing for a division of journals into recorder or archival publications and newspaper or current awareness journals. Indeed, as long ago as 1939 Bernal suggested that the traditional scientific journal could be replaced by a system of distributing abstracts of articles sent to a central source, with interested readers obtaining copies of the full papers on request. Fox repeated Bernal's suggestions in his Heath-Clark lectures in 1964, ${ }^{4}$ going on to say that, as with the overgrowth of other populations, the preferable remedy was prevention-some form of contraception. Yet, though this concept was echoed as recently as 1979 by Durack (who proposed that each individual could 
be restricted to 50 scientific articles in his lifetime), ${ }^{5}$ and just as the population of the world has grown from 3220 million in 1964 to 4336 million in 1979, so medical journals have ignored would-be preventionists and their growth has continued unchecked.

Could indeed, Ziman wonders, such growth be a sign of health rather than disease in the scientific community. ${ }^{6}$ Professor Derek de Sola Price has shown that scholars have read and written at much the same rate over the past three centuries, and for much the same reasons. ${ }^{7}$ New journals are often started because existing ones overlook the fact that the disciplines of many readers cross rigid boundaries-for instance, they are not pure cardiologists but chemical pathologists or immunologists with an interest in cardiology.

History shows that when faced with the threat of information overload the scientific community has always found a solution -initially with books and encyclopaedias, then with abstracting journals, and latterly with data banks. Now there are some 300 data banks, which in the past has been the magic number in this growth process when some new solution has had to be devised. So where can the harassed researcher and librarian go? The answer may lie in adding yet another filter to our system of quality control. Traditionally filtration starts with the grant agencies, which scrutinise research protocols, and continues with the journals, many of which submit the resulting articles for peer review by expert assessors and if the papers are published sometimes to criticism in a correspondence column; other factors in this process include whether the message of the articles becomes incorporated into knowledge bases, such as important review articles and textbooks, or is quoted as shown by the Science Citation Index, developed by Garfield-or even whether a library committee decides to purchase the particular journal in which the article is published.

Can this filtration system be improved? Probably it can: for in one analysis (for the physical sciences) only $10-14 \%$ of authors were found to write up their work to contain useful information $^{8}$; a quarter to a half of all published articles are never cited even once ${ }^{9}$; and in at least three instances consensus analysis by experts of the published work on one topic has shown that only between 10 and $15 \%$ of articles were important. ${ }^{10}$ To see whether filtration by consensus might be able to help readers an experiment was conducted a few years ago to review the publications on viral hepatitis. ${ }^{11}$ In the English language serials in the Medline file over 10 years ago there were no fewer than 16000 citations. Nevertheless, by using 40 recent reviews on the subject a knowledge base of only 575 original articles was constructed. When a panel of 10 experts was then asked to update this base they were confronted with another 5700 new articles published in the previous two and a half years-clearly an impossible load for any individual to come to grips with.

The solution was to look at which journals had published the initial 575 articles: $47 \%$ of these had appeared in only five journals, and $80 \%$ in 18 journals (among which, I was glad to see, was the $B M \mathcal{F}$ ). By using only the 18 journals, therefore, the experts were able to update the knowledge base and to arrive at a final number of only 620 articles.

Though there have been rumours that this type of filtration by consensus might be extended to other important topics, and readers were promised an update of the hepatitis knowledge base itself, nothing else seems to have been published. This lack of follow-up is unfortunate because, despite the work entailed (and the stress on the members of the consensus team), the new approach does represent a method of coping with "the literature." Moreover, though this selection is done on grounds of quality, it does not affect the ability to retrieve all the articles on the Medline file. In time, indeed, the Index Medicus and Medline might be arranged similarly to the Michelin Guide: articles recognised as important by a consensus team might be given three stars, other articles with a high citation index two stars, articles with a lower citation index one star, and articles that had never been cited even once no star. Such a scheme might reflect the obvious-that some articles are better than others-without imposing any censorship on retrieval.

In the meantime the harassed reader is still faced with many of the old problems and must rely on help from other authors and editors. The former should make their articles brief and clear on the lines so admirably laid out by Eli Chernin, a previous book review editor of the New England Fournal of Medicine. ${ }^{11}$ Editors should not only explain their roles (and in the book Arnold Relman, now editor of the same journal, has some wise words to say on these ${ }^{12}$ ) but should now be concentrating on trying to develop objective guidelines to enable assessors and readers to judge quality. In the $B M \mathcal{F}$ Altman has argued forcefully for a code of statistics for biomedical journals ${ }^{13}$ and in Coping with the Biomedical Literature Sackett lists the elements that ought to be given in articles about a diagnostic test, the clinical course and prognosis of disease, diagnostic tests for causation, and the risks and benefits of treatment. ${ }^{14}$. If, then, for biomedical journals the last twenty years has seen a preoccupation with questions of originality and ethics possibly the next twenty may be concerned with those of quality.

STEPHEN LOCK

Editor, British Medical fournal

1 Warren KS ed. Coping with the biomedical literature. New York, Praeger, 1981. Price $£ 22$.

2 Warren KS. Selective aspects of the biomedical literature. In : Warren KS, ed. Coping with the biomedical literature.

${ }^{3}$ Bernal JD. Social function of science. Cited by Fox $\mathrm{T}$ Crisis in communication. London, Athlone Press, 1965.

${ }^{4}$ Fox T. Crisis in communication. London: Athlone Press, 1965.

${ }^{5}$ Durack DT. The weight of medical knowledge. N Engl f Med 1978;298: 773-5.

${ }^{6}$ Ziman JM. The proliferation of scientific literature. Science 1980;208: 369-71.

7 Price D de S. The development and structure of the biomedical literature. In: Warren KS, ed. Coping with the biomedical literature.

${ }^{8}$ Branscomb LM. Misinformation explosion: is the literature worth reviewing. Cited by Warren KS. ${ }^{2}$

${ }^{9}$ Garficld E. The citation index as a quality information filter. Cited by Goffman W. The ecology of the biomedical literature and information retrieval. In: Warren KS, ed. Coping with the biomedical literature.

10 Goffman W. The ecology of the biomedical literature and information retrieval. In: Warren KS, ed. Coping with the biomedical literature.

11 Bernstein LM, Siegal ER, Goldsten CM. The hepatitis knowledge base. Ann Intern Med 1980;93:169-81.

12 Chernin E. First, do no harm. In: Warren KS, ed. Coping with the biomedical literature.

${ }^{13}$ Relman AS. Journals. In: Warren $\dot{\mathrm{K} S}$, ed. Coping with the biomedical literature.

14 Altman DG. Improving the quality of statistics in medical journals. $\mathrm{Br} \mathrm{Med}$ f 1981 ;282:44-7.

15 Sackett DL. Evaluation : requirements for clinical application. In: Warren $\mathrm{KS}$, ed. Coping with the biomedical literature.

\section{Correction}

\section{What has happened to charity?}

In the leading article by Professor Roy Calne (3 April, pp 998-9), the fifth sentence of the second paragraph on $p 999$ should have read "If the deceased's wishes are not known...." 